\title{
A produção textual na esfera académica: desafios concernentes ao ato de dizer materializados em gêneros do discurso secundários
}

The textual production in the academic sphere: challenges concerning the act of saying materialized in secondary discourse genres

Mary Elizabeth Cerutti-Rizzatti Universidade Federal de Santa Catarina (UFSC), Florianópolis, SC, Brasil.

Suziane da Silva Mossmann

Universidade Federal de Santa Catarina (UFSC), Florianópolis, SC, Brasil.

Resumo: O artigo discute desafios atinentes aos usos da escrita materializados em gêneros do discurso da esfera acadêmica, considerados a participação de graduandos do curso de Letras Português da Universidade Federal de Santa Catarina, na disciplina de Produção Textual. A fundamentação teórica articula concepções de língua, sujeito e texto ancoradas na ótica bakhtiniana, vigotskiana e do letramento (CERUTTI-RIZZATTI; MOSSMANN; IRIGOITE, 2013). Quanto à metodologia, caracteriza-se como estudo de caso tipo etnográfico (ANDRÉ, 2008). Sobre a noção de inteligibilidades, enfatiza-se a tensão da constituição dos participantes em relação às demandas acadêmicas para a produção textual, especialmente, quanto às especificidades intersubjetivas/intrassubjetivas do dizer acadêmico.

Palavras-chave: Produção Textual Acadêmica. Esfera Acadêmica. Eventos e Práticas de Letramento. Simpósio Conceitual.

Abstract: This paper discusses challenges related to the uses of writing materialized in discourse genres in the academic sphere, considering the participation of undergraduates of the Language - Portuguese course in the Universidade Federal de Santa Catarina (UFSC) in the Textual Production subject. The theoretical foundation articulates conceptions of language, subject and text anchored in the Bakhtinian, Vigotskian and literacy views (CERUTTIRIZZATTI; MOSSMANN; IRIGOITE, 2013). The methodological approach is ethnographic case study (ANDRÉ, 2008). Concerning the intelligibilities, it is enphasized the tension of the participants constitution in relation to the academic demands for textual production, specially, as to the intersubjective/intrassubjective specificities of the academic speech. 
Key-words: Academic textual production. Academic sphere. Literacy events and practices. Conceptual symposium.

Mary

Elizabeth

Cerutti-

Rizzatti

Suziane

da Silva

Mossmann

\section{Introdução}

A produção textual na esfera acadêmica passou a ser tomada como uma questão a ser problematizada e, portanto, como objeto de estudo, a partir do ingresso de estudantes constituídos em relações que se estabelecem com base em práticas de letramento divergentes das esperadas na esfera acadêmica (LILLIS, 2001). Estudos desenvolvidos por Lea e Street (1998), Ivanic (1998), Lillis (2001) e Zavala (2010) apontam para a urgência de se compreender a participação desses mesmos sujeitos em eventos de letramento na esfera acadêmica, depreendendo especificidades de tal participação e conflitos relativos às diferentes perspectivas postas em contato, de modo a se buscar desenvolver ações didático-pedagógicas que não apenas estejam restritas à constatação do insucesso acadêmico dos estudantes no que tange à materialização do dizer em produções textuais de gêneros do discurso secundários exigidos na esfera em questão ${ }^{1}$.

Segundo Zavala (2010, p. 74), o letramento na esfera acadêmica oculta-se em um discurso aparentemente neutro, o que se associa certamente aos pressupostos do Modelo Autônomo de Letramento (STREET, 1984). Nesse sentido, o pensamento acadêmico, vinculado a noções de racionalidade, de criticidade e de abstração "assume a absoluta clareza de representação do conhecimento como veículo de uma mente racional e científica" (ZAVALA, 2010, p. 74). Representações como essas remetem à urgência de se lançar mão de discussões que considerem os usos da escrita como prática social, extrapolando as dimensões instrucional, tecnológica e cognitiva, para contemplar questões relacionadas à subjetividade, ao poder e às epistemologias colocadas em confronto. Nesse contexto, importa destacar a esfera escolar/acadêmica como espaço de luta, de debates, de circulação e de construção de conhecimentos que não se restrinjam ao que é entendido como dominante, de

1 O presente artigo apresenta-se como um recorte da dissertação de Mossmann (2014), cujo objeto de discussão buscou apresentar inteligibilidades para caracterização da participação de graduandos de Letras/Português em eventos de letramento na esfera acadêmica nos quais lhe é requerido o ato de dizer, via modalidade escrita, em gêneros do discurso cujos textos se vinculam aos letramentos dominantes. $\mathrm{O}$ estudo mencionado contou com oito participantes de pesquisa, matriculados em $1^{\mathrm{a}}, 2^{\mathrm{a}} \mathrm{e}$ $3^{\mathrm{a}}$ fases do curso de Letras/Português da Universidade Federal de Santa Catarina. 
modo que outras formas de pensar o mundo tenham lugar dentro desse espaço que propõe aos sujeitos encontros com as produções culturais da humanidade, com as sistematizações de conhecimentos e com os modos de organizar possivelmente nossas vivências e convivências em uma sociedade tão diversa.

Discussões dessa natureza, importa enfatizar, tornaram-se presentes e possíveis em decorrência de uma ampliação do olhar científico para as concepções de língua, de sujeito e de texto, questão amplamente compartilhada, mas que requerem menção, nesse contexto, para justificar o entrecruzamento de perspectivas teóricas e filosóficas que se constituem ancoradas em uma abordagem histórico-cultural (com base em CERUTTI-RIZZATTI; MOSSMANN; IRIGOITE, 2013). Entende-se, nesses termos, que não basta olhar para a língua como sistema, sendo

A produção textual na esfera acadêmica imprescindível uma articulação conceitual voltada para a compreensão dos desafios de se trabalhar com a dinamicidade da língua. Desse modo, parece nodal que se assumam determinadas concepções e que se ancorem nelas as relações de ensino e pesquisa. Para o simpósio conceitual mencionado, parte-se da compreensão de língua como interação (VOLOSHINOV, 2009 [1929]) de sujeitos singulares e situados na relação entre cotidiano e história (HELLER, 1970), os quais lançam mão dos usos da língua entendidos, nesse contexto, como instrumento psicológico de mediação simbólica (VIGOTSKI, 1968). A língua, nesse sentido, constitui-se, em uma perspectiva vigotskiana, como intercâmbio social e como eixo de organização do pensamento; para Voloshinov (2009 [1929]), ela é arena de lutas sociais, sendo materialização das ideologias oficiais e do cotidiano, de modo que diferentes práticas de letramento entrem em conflito em eventos de letramento dos quais participam os sujeitos (STREET, 1984; BARTON, 2007; IVANIC, 1998; LEA; STREET, 1998; LILLIS, 2001; ZAVALA, 2010).

Desse modo, considerando propor uma discussão que amplie o olhar acerca dos desafios relativos à produção textual escrita na esfera acadêmica e partindo dos pressupostos teóricos apresentados, organiza-se o presente artigo em três seções: a primeira trata das ancoragens teóricas relativas à produção de textos na esfera acadêmica a partir do supracitado simpósio conceitual; a segunda apresenta procedimentos metodológicos e as diretrizes de análise; e a terceira seção propõe-se a discutir os dados selecionados a partir do estudo de Mossmann (2014). 
Importa, enfim, informar acerca dos participantes desse estudo que o principal critério para seleção para essa pesquisa era referente à realização de toda a escolarização em redes de ensino públicas. Ou-

Mary tro critério importante dizia respeito à condição socioeconômica do Elizabeth participante. A opção por trabalhar com tais critérios justifica-se pela Cerutti- busca de compreensão e de propostas de ação relativas ao ingresso de Rizzatti estudantes que têm sido considerados casos de insucesso acadêmico no que concerne à produção textual acadêmica. $\mathrm{O}$ olhar para os desafios

Suziane concernentes ao ato de dizer marca-se em relação a essa delimitação da Silva sociocultural e econômica.

Mossmann

\section{A produção textual escrita na esfera acadêmica}

A partir das discussões empreendidas acerca da produção de textos nas áreas da Linguística Textual e da Linguística Aplicada, considerando elementos relativos à textualidade, à concepção de texto, de língua, bem como elementos centrais para o trabalho com a escrita e leitura de textos de estudantes, importa reiterar que ancoragens teórico-epistemológicas balizam a ação didático-pedagógica em sala de aula. Ao se compreender o texto como materialidade linguístico-discursiva que tem função social e que se produz para cumprir determinados objetivos, em determinados contextos, espera-se que o agir docente esteja atento a distanciamentos e aproximações de modo a facultar condições de apropriação dos conceitos implicados nas práticas e nos processos envolvendo a modalidade em questão, possibilitando a produção aos sujeitos, de modo que o texto seja pensado com base em uma dimensão intersubjetiva e intrassubjetiva (CERUTTI-RIZZATTI; CASSOL DAGA; CATOIA DIAS, 2015).

Tal proposição justifica-se teoricamente pela articulação de perspectivas teóricas pautadas em um horizonte epistemológico compartilhado: o ideário histórico-cultural. Parte-se de uma concepção de língua que lida conceitualmente com a vertente psicológica a partir dos estudos vigotskianos, considerando, assim, as relações entre aprendizagem e desenvolvimento dos sujeitos e o papel da linguagem como instrumento psicológico, envolvendo, ainda, conceitos relativos à mediação, à formação de conceitos, à compreensão da memória, da percepção e da atenção em favor de apropriações conceituais que facultam aos sujeitos deslocamentos em suas zonas de desenvolvimento no que se refere aos conhecimentos acumulados ao longo da história (DUARTE, 
2016). Em relação ao simpósio conceitual mencionado, evoca-se ainda a concepção de língua tomada dos estudos bakhtinianos, relacionando conceitos basilares do pensamento do Círculo de Bakhtin: interação social, gêneros do discurso, ideologia, dialogia, discurso reportado. Já em se tratando dos estudos do Letramento, considerando a vertente vinculada às discussões empreendidas por pesquisadores do grupo do Reino Unido, parte-se de reflexões já consolidadas em relação à cultura escrita, aos conceitos de eventos e práticas de letramento, bem como de letramentos dominantes e vernaculares.

Nesse contexto, retomando o olhar para a cultura escrita, na dimensão da língua entendida sob os contornos delimitados até aqui, entende-se a produção textual escrita como produção humana que articula a dimensão intersubjetiva e intrassubjetiva. Importa em re-

A produção textual na esfera acadêmica lação à primeira dimensão compreender, desse modo, que os Interactantes lançam mão dos usos sociais da língua em sua modalidade escrita, considerando e compreendendo a relevância de se pensar que todo texto-enunciado (BAKHTIN, 2010 [1952-53]) concretiza uma representação/interpretação da realidade, objetivando provocar no outro reações-resposta, sendo, portanto, sempre endereçado a alguém, seja um interlocutor real ou em potencial, questão também discutida por Beaugrande e Dressler (1981) em relação aos fatores de textualidade em uma dimensão textual-discursiva (intencionalidade, aceitabilidade, informatividade, situacionalidade, intertextualidade, coesão e coerência). Além disso, todo texto-enunciado implica, segundo Bakhtin (2010 [1952-53]), expressividade materializada na intenção do falante e uma relação axiológica e ideológica em relação ao objeto do discurso. Para o autor, a situação dos participantes da interação define a forma e o estilo do enunciado, de maneira que se constituem como tipos relativamente estáveis, ou seja, os diferentes gêneros do discurso. $O$ ato de dizer, conceito fundamental que se refere à vida, ao pensamento como ato, como não álibi para o existir no mundo e implica relação entre istina e pravda, singular e universal, mundo da vida e mundo da teoria, de acordo com Bakhtin (2010 [1920-24]), é entendido, nesse contexto, na relação com o gênero e funciona conceitualmente para explicar o modo social de organizar, orientar, regular e significar a ação social. Em Voloshinov (2013 [1930]), os conceitos de gêneros primários e secundários definem-se pela relação com os horizontes espacial, temporal, axiológico 
e temático. Para Bakhtin (2010 [1952-53]), os índices de totalidade caracterizam a organização do enunciado como unidade discursiva, estando em foco o conteúdo temático, o estilo e a configuração com-

Mary posicional, cuja relação se estabelece a partir de aspectos que caracElizabeth terizam o gênero como primário ou secundário.

Cerutti-

Todo gênero do discurso vincula-se a uma esfera e a um crono-

Rizzatti topo, os quais evocam ideologias e axiologias relativas ao cotidiano ou ao domínio tomado como oficial. Ler e escrever textos são pro-

Suziane cessos, então, que precisam articular a dimensão intersubjetiva à inda Silva trassubjetiva, partindo da concepção que assume uma abordagem de língua como instrumento, cujo funcionamento se dá como intercâmbio social e como organização do pensamento em uma perspectiva vigotskiana, de modo que faculta o encontro de sujeitos que se constituem por meio dos conflitos e contradições presentes nas diferentes representações/interpretações da realidade. A discussão da leitura e da produção textual, nesses termos, precisa ser feita, de acordo com Britto (2012), a partir da ótica dos gêneros. Ler e escrever é ler e escrever textos que se materializam em diferentes gêneros e que carreiam consigo, nessas circunstâncias, especificidades que delimitam os diferentes usos, pensando, nesse sentido, nos gêneros do discurso secundários concernentes à esfera acadêmica e à historicização desses mesmos usos em relação ao cronotopo e às demandas requeridas pelos interactantes que fizeram/fazem parte da conformação das particularidades de tal esfera.

Compreensão dessa ordem conduz, assim, à perspectiva de que a produção de textos transcende a materialidade linguística em uma dimensão sistêmica, sendo também fundamental, mas não suficiente, para se discutir os diferentes modos de organizar o dizer na esfera acadêmica. Os processos envolvendo a modalidade escrita da língua implicam, dessa maneira, que a produção seja abordada, considerando a concepção de língua como prática social (KLEIMAN, 1995), como atividade humana (BAKHTIN, 2010 [1952-53]), como trabalho complexo que demanda articulação entre dimensões intersubjetivas - interactantes interagindo por meio de gêneros do discurso em esferas específicas, situadas em um cronotopo - e intrassubjetivas - ativação de conhecimentos prévios (linguísticos, interacionais e de mundo), agenciamentos de esquemas cognitivos e realização de inferências (a partir de CERUTTTI-RIZZATTI; CASSOL DAGA; CATOIA DIAS, 2014). 
Nesses termos, tomando por base a articulação já mencionada entre as dimensões intra e inter, importa ler e produzir textos em gêneros, considerando aspectos interacionais, textuais, linguísticos e normativos. No que se refere ao primeiro eixo, interacional, parte-se de conhecimentos de mundo - elementos contextuais, tomando o ato de dizer elaborado por interactantes em relação a elementos concernentes ao tempo histórico e ao espaço social; à esfera, como organização do texto que prevê a circulação em determinados contextos de uso; além do suporte, tomado como materialização do texto em relação aos diferentes meios de circulação; no que tange aos índices de totalidade dos gêneros, tem-se estilo, composição e tema, de modo que é fundamental atentar para o léxico e a gramática em um arranjo que marca o estilo de escrever de cada sujeito em relação à paragrafação, ao desenvolvimen-

A produção textual na esfera acadêmica to do tema, à apresentação do conteúdo abordado em se tratando dos elementos já apresentados.

No que tange ao segundo eixo, textual, parte-se também de conhecimentos de mundo contextuais, e o arcabouço conceitual apresentado como instrumentalização de compreensão da realidade e de atuação dos sujeitos por meio dos diferentes usos da língua precisa ser articulado aos demais aspectos, visando a uma maior inteligibilidade acerca do conceito de texto e de textualidade na dimensão dos usos sociais da língua. Assim, temos os já mencionados fatores de textualidade: informatividade, apresentada como conteúdo adequado ao gênero - dado $x$ novo; intencionalidade, tomada como fios lançados pelo sujeito que escreve ao seu leitor (real ou potencial); aceitabilidade, prevendo articulações possíveis em relação aos fios lançados pelo autor; situacionalidade, relação com a esfera, suporte, tempo e espaço e a organização do texto visando tais aspectos; intertextualidade, relações com outros textos em relação à forma a ao conteúdo: uso de citações diretas, indiretas, bem como utilização de paráfrases. Ainda em relação ao eixo textual, mas em uma dimensão dos conhecimentos linguísticos co-textuais, é preciso levar em consideração a coerência, em se tratando da manutenção e da progressão do eixo temático, não-contradição e articulação de fatos, dados e opiniões; e a coesão, como materialidade dos usos da língua em se tratando dos processos de referenciação, seleção lexical e articulação dos elementos empreendidos em favor de um projeto de dizer $(\mathrm{KOCH}$, 2002; BEAUGRANDE; DRESSLER, 1981; CHAROLLES; 1988; COSTA VAL, 1991; ANTUNES, 2005). 
No que se refere aos aspectos normativos, os conhecimentos de mundo e linguísticos dizem respeito a elementos que podem ser considerados de superfície, mas, de acordo com Mossmann (2014, p. 347), essa questão:

Mary

Elizabeth

Cerutti-

Rizzatti

Suziane

da Silva

Mossmann

156

[...] parece, por vezes, periférica, no entanto, em determinados momentos das vivências na Universidade, especialmente em contextos de maior inserção, ou ainda, em condições em que o sujeito se aproxima da condição de insider, o reconhecimento da funcionalidade e o domínio dessas mesmas normas técnicas torna-se fundamental para um estudante de Letras, haja vista que os trabalhos acadêmicos, a produção acadêmica configura-se em relação às especificações de tais normas e padronizações.

Sendo, desse modo, um aspecto tomado como definitivo em relação à condição do graduando se constituir como insider na esfera acadêmica. Ainda em relação a tal eixo, considera-se, a saber: ortografia, acentuação, pontuação, concordância, regência, bem como reconhecimento das normas técnicas, a exemplo da Associação Brasileira de Normas Técnicas (ABNT).

Nesses termos, escrever e ler textos em gêneros do discurso secundários na esfera acadêmica requer concepções de língua e texto norteadoras de uma ação didático-pedagógica enfocada no desvelamento das práticas institucionais do mistério ${ }^{2}$ (LILLIS, 2001), de modo que as intervenções realizadas pelos docentes nos textos produzidos pelos acadêmicos facultem uma maior inserção nas práticas de letramento referentes às atividades desempenhadas nessa esfera. Importa atentar para os eixos relativos à interação situada; ao texto-enunciado e ao mundo vivido; à tessitura linguístico-textual; ao dito e ao não-dito; bem como ao eixo relativo à decodificação e ao mapeamento dos recursos lexicais, gramaticais e fraseológicos (CERUTTI-RIZZATTI; CASSOL DAGA E CATOIA DIAS, 2014). Acrescenta-se, considerando a discussão da produção de textos acadêmicos, que tais aspectos precisam ser levados em consideração tanto na escrita, quanto no modo como se lê, avalia e

2 Lillis (2001) introduz o conceito de práticas institucionais do mistério para tratar de aspectos interacionais relativos à participação de acadêmicos com práticas de letramento divergentes das práticas relativas às da esfera acadêmica e aos modos de se lidar com os efeitos de tais divergências na escrita e na leitura, por parte dos membros da instituição, considerando a apropriação do arcabouço teórico-metodológico implicado em uma maior ou menor inserção nas atividades atinentes às especificidades da esfera em questão. 
compreende a participação dos sujeitos em diferentes eventos de letramento na esfera acadêmica. Ler e escrever textos em uma perspectiva interacional requer um arcabouço teórico-metodológico que dê conta de atentar para o conteúdo temático abordado e para a configuração composicional materializada por meio dos recursos linguísticos, textuais, interacionais e normativos dos quais os sujeitos lançam mão ao escrever na universidade. Tal reconhecimento coloca, nesses termos, aos sujeitos participantes dessa esfera o desafio de dominar mais do que o objeto teórico, tomado em uma dimensão científica, conforme apontam Zavala (2010), Lillis (2001) e Lea; Street (1998).

\section{Procedimentos metodológicos e diretrizes de análise}

O estudo em questão apresenta um recorte da dissertação de Mossmann

A produção textual na esfera acadêmica $(2014)^{3}$ e recorre aos dados gerados a partir da realização da presente pesquisa. Assim, importa retomar que as discussões e reflexões empreendidas neste artigo visam abordar inteligibilidades acerca do fenômeno do letramento na esfera acadêmica no que se refere à participação de graduandos do Curso de Letras/Português em eventos de letramento que têm lugar nessa mesma esfera, considerando, para tanto, implicações da constituição subjetiva dessa mesma participação no que entendemos como ato de dizer, bem como dos desafios depreensíveis a partir do processo de apropriação dos letramentos dominantes materializados na escrita requerida na esfera já mencionada.

O objeto de discussão do presente artigo constitui-se como um estudo de caso de tipo etnográfico (ANDRÉ, 2008) com abordagem qualitativa de base interpretativista (MASON, 1996); com base em dois participantes de pesquisa, matriculados na primeira fase do curso de Letras/ Português da Universidade campo de estudo, mais especificadamente na disciplina de Produção Textual Acadêmica. Os dados foram gerados a partir de instrumentos como observação participante, notas em diário de campo, entrevistas e pesquisa documental.

Como diretrizes de análise, toma-se o diagrama integrado, cuja base teórico-metodológica fundamenta-se em um simpósio conceitu-

3 O mencionado recorte refere-se fundamentalmente ao uso de dados gerados em entrevistas, observação participante, notas em diário de campo e pesquisa documental, os quais foram decorrentes do acompanhamento de 8 participantes, graduandos matriculados nas três primeiras fases do Curso de Letras Português da UFSC. Como objeto desse artigo, lançar-se-á mão de dados referentes a dois participantes matriculados na primeira fase, na disciplina de Produção Textual Acadêmica. 
al, defendido e apresentado em Cerutti-Rizzatti, Mossmann e Irigoite (2013). A seguir, retoma-se o mencionado diagrama, que foi delineado a partir da ressignificação do diagrama de Hamilton (2000):

Mary
Elizabeth
Cerutti-
Rizzatti

Suziane
da Silva
Mossmann

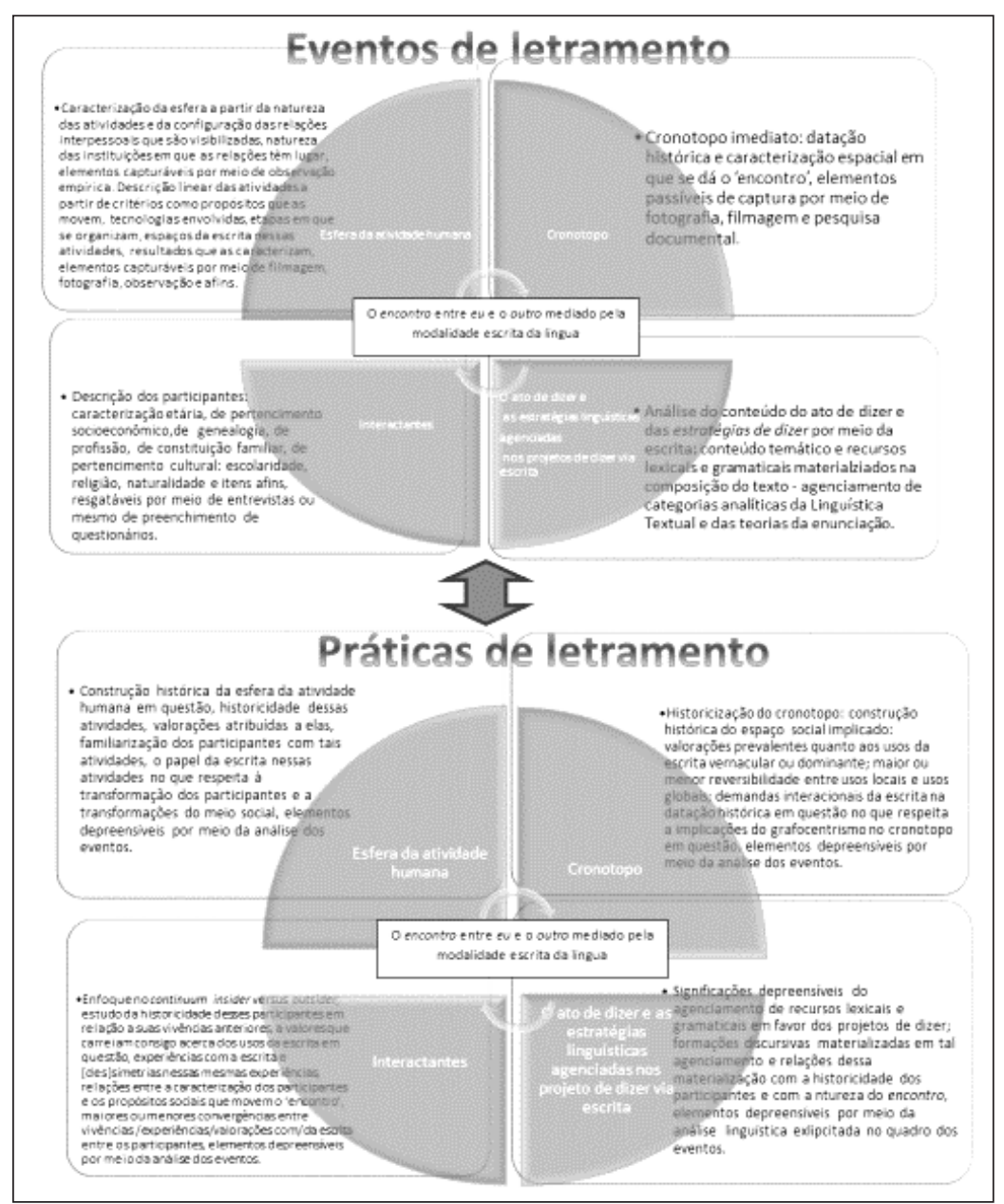

Figura 1 - Diagrama integrado: inter-relação entre eventos e práticas de letramento como modelo analítico. Fonte: Cerutti-Rizzatti; Mossmann; Irigoite, 2013

Em relação ao diagrama integrado, o eixo articulador parte da interação, em um conceito filosófico tomado a partir de Ponzio (2010), denominado como encontro da palavra outra com a outra palavra. A materialidade do ato de dizer, nesses termos, põe em relação as situações em que a língua se concretiza em sua modalidade escrita, nesse caso, levando ao conceito de eventos de letramento. Os usos da língua em sua modalidade escrita associados às discussões bakhtinianas facultam uma 
compreensão do processo de interação dos sujeitos, considerando as seguintes categorias de análise: i) caracterização da esfera; ii) caracterização dos interactantes; iii) atenção ao cronotopo, o qual implica datação histórica e caracterização espacial no qual se dá a interação; iv) análise do conteúdo do dizer materializado em gêneros do discurso, partindo dos índices de totalidade. O segundo eixo do diagrama ancora-se no conceito de práticas de letramento e toma a partir de especificidades de tal conceito as categorias sistematizadas anteriormente como referentes às diretrizes de análise.

Em relação ao objeto de discussão desse artigo, importa atentar para o primeiro eixo do diagrama, de forma a analisar as categorias a partir dos eventos de letramento, considerando particularidades do gênero em questão no que se refere à imprescindibilidade do recorte. No

A produção textual na esfera acadêmica que concerne aos participantes de pesquisa, interactantes em relação com textos materializados em diferentes gêneros do discurso secundários e com demandas da esfera acadêmica concretizadas em ementas, planos, atividades e intervenções tomadas como feedbacks ou correções ${ }^{4}$, faz-se relevante introduzir WKC.-1 e GDL.-1, ambos matriculados na disciplina de Produção Textual Acadêmica, oriundos de escolas de ensino público. Dentre os participantes selecionados para o presente estudo, há questões que singularizam cada sujeito. No entanto, há elementos tomados em uma dimensão macro que se apresentam como compartilhadas por eles, a saber: uma nomeada frustração vivenciada em torno da escolarização básica, considerando o pouco espaço dedicado à escrita e à leitura, a constituição de um corpo docente itinerante, a rarefação de feedbacks relativos à sua participação nas atividades escolares; a disseminação do Mito da Educação Superior, especialmente na esfera familiar, partindo-se do pressuposto de que o acesso à esfera acadêmica seria suficiente para se atingir outro status na vida profissional e pessoal, questão amplamente abordada por Zavala (2010) ${ }^{5}$. Ainda em relação aos participantes, ambos são recém-egressos do Ensino Médio e apontam sentirem grande desconforto relativo à leitura e à produção de textos na esfera acadêmica.

4 Lillis (2001) propõe o termo talkback, considerando que a intervenção que o professor faz no texto do aluno precisa ser tomada em uma perspectiva dialógica, compartilhando, nesses termos, do ideário bakhtiniano.

5 Todos os dados apresentados aqui foram mencionados em entrevistas pelos participantes do supracitado estudo, o que pode ser consultado em Mossmann (2014). 


\section{Um olhar analítico acerca dos desafios e obstáculos concernentes ao ato de dizer nos gêneros do discurso}

Antes de adentrar a questão que move essa discussão, é preciso tratar

Mary de especificidades relativas às demandas da esfera acadêmica, uma vez

Elizabeth que, para os participantes desse estudo, as ressignificações de suas prá-

Cerutti- ticas de letramento constituíram-se de maneira conflituosa, em uma

Rizzatti constante tensão entre o sentir-se insider e/ou outsider nessa mesma esfera (com base em Kramsch, 1998). Tais tensões são decorrentes das

Suziane divergências apresentadas na participação em eventos de letramento da Silva sustentados (ou não) por práticas que se aproximam ou divergem das Mossmann

A respeito de tais divergências, evidenciam-se, nesses termos, aspectos que deslocam a constituição subjetiva dos participantes de pesquisa, no âmbito da leitura, considerando, assim, o cânone literário, valorizações e legitimações de gêneros do discurso secundários, bem como um percurso de discussões que permita inserção efetiva em se tratando dos processos implicados na leitura desses mesmos textos; no âmbito da produção textual no que se refere aos modos de dizer, os graduandos apontam outros olhares para a escrita no que concerne à criticidade, argumentatividade, apropriação da norma culta e das normas técnicas, agenciamento de conhecimentos atrelados a um posicionamento considerado crítico e científico, domínio da orquestração de vozes materializadas no discurso reportado, bem como ressignificações referentes a uma compreensão de um ato de dizer materializado nos gêneros e suas especificidades relacionadas à configuração composicional, aos recursos linguísticos e ao conteúdo temático.

Faz-se necessário mencionar que os graduandos entram em conflito mediante tais aspectos e passam a rever seus modos de dizer, no entanto, esse movimento apresenta-se, de acordo com Mossmann (2014), como uma tensão entre uma acomodação que concede aos novos modos de produzir textos na esfera acadêmica sem que o sujeito compreenda efetivamente o que está ali implicado, estando muitas vezes em uma fase do aprendizado que implica imitação, de acordo com o pensamento vigotskiano, mas que precisa superar essa condição atingindo outros processos relativos ao desenvolvimento, caso contrário, a acomodação se estabelece e pode implicar uma pseudoparticipação que se estende ao longo do processo de formação. A apropriação dos conceitos e a ressignificação atinente à participação implica, nessas circunstâncias, 
ação organizada do interlocutor mais experiente visando ao desenvolvimento de novas estruturas relativas aos comportamentos e conceitos por parte dos graduandos, considerando, aqui, especificidades da esfera acadêmica. $O$ outro movimento apresentado em um continuum que pode ou não se estabelecer diz respeito à aprendizagem e ao movimento de internalização dos conceitos e comportamentos já mencionados. O aprendizado é assim aspecto fundamental para o desenvolvimento das características psicológicas humanas e culturalmente organizadas, nesse contexto, considera-se o ato de dizer em gêneros pertencentes à esfera acadêmica.

Produzir textos nessa esfera para sujeitos que, muitas vezes, carregam consigo práticas de letramento distanciadas das expectativas de práticas requeridas na esfera acadêmica, concretiza-se como um grande

A produção textual na esfera acadêmica desafio, chegando a se constituir em alguns contextos como obstáculos para a permanência no curso escolhido. As vivências por parte desses graduandos na esfera acadêmica colocam muitas vezes um contexto de diglossia, uma vez que o acadêmico precisa lançar mão de outros modos de organizar os usos que faz da língua em sua modalidade oral e escrita (ZAVALA, 2010; LEA; STREET, 1998; IVANIC, 1998). Para intervir, nesse sentido, no cenário que se configura como problemático, parece assim ser fundamental uma compreensão que atente para a instrumentalização dos sujeitos em relação aos aspectos interacionais, textuais, linguísticos e normativos. Assim, a partir da observação participante de quatro aulas semanais de Produção Textual Acadêmica durante um semestre, da realização de notas em diário de campo, bem como da realização de três entrevistas com cada um dos participantes envolvidos nesse estudo e da análise dos textos produzidos por esses sujeitos nas aulas acompanhadas, foi possível depreender um conjunto de desafios relacionados aos modos de dizer nos gêneros do discurso; aos dizeres legitimados na esfera acadêmica, o que inclui o tensionamento da palavra outra no discurso reportado; e, por fim, às normalizações dos projetos de dizer em relação às normas padrão e ABNT.

No que respeita aos modos de dizer materializados nos diferentes gêneros solicitados, identificou-se, a partir dos textos, dos relatos dos participantes de pesquisa e dos comentários feitos pelos docentes nos mesmos textos, dificuldades referentes à configuração composicional no que concerne às especificidades intersubjetivas, à organização de um dizer que se configura de uma maneira ou de outra conforme as relações 
estabelecidas e às regularidades concernentes ao gênero em questão. 0 não reconhecimento de tais especificidades foi marcado em determinados contextos, por meio das intervenções dos docentes, como dizeres que

Mary se configuravam como atípicos, caso do resumo informativo:

Elizabeth

Cerutti-

Rizzatti

Suziane

da Silva

Mossmann

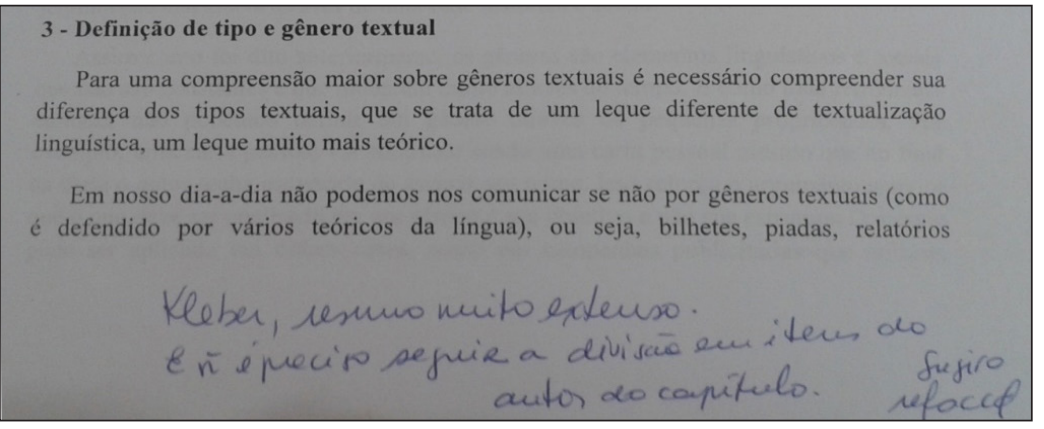

Figura 2 - excerto de resumo elaborado por WKC.-1 - disciplina de Produção Textual Acadêmica. Fonte: Mossmann (2014)

Dois excertos de fala de WKC.-1 constituem-se como relevantes para que se possa propor um olhar analítico acerca dos desafios relativos à produção textual acadêmica nesse contexto. Seguem:

(1) Acho que talvez uma dificuldade seja ofato / mas isso tem muito a ver com o Ensino Médio, é que nós chegamos aqui com muitas deficiências de::: escrita mesmo, os alunos chegam aqui, e o professor pede "Ah, façam uma resenha". o aluno não sabe muitas vezes o que é essa resenha, o que que diferencia ela de um resumo, como organizar isso, ou então faz um fichamento; "Como que eu vou fazer um fichamento?", entende? Nem sempre é ensinado antes e muitas vezes nós não sabemos o que fazer (WKC.-1, entrevista realizada em 10 de julho de 2013, ênfases nossas).

(2) Esse texto mesmo, me deu muita dor de cabe:::ça. Eu LI (+) o texto que ela mandou e eu não entendi NADA. Eu pensei "meu Deus do céu!" Parecia que tudo que tava ali era importante e de fato, era, só que eu, eu não sabia como resumir aquilo, eu não sabia como fazer menor que aquilo. Então, eu acabava pegando muita coisa, eu não consegui anular a divisão de tópicos, parecia que eu tava deixando alguma coisa de fora e se eu não fizesse isso, acho que ficaria incompleto. Então, esse texto ali me deu muita dor de cabeça, foi difícil de sintetizar. (+) Eu tive dificuldade por causa do assunto do texto, 
eu lia e relia e claro que::: eu consegui fazer a atividade, mas tem muita coisa que eu ainda não entendi naquele texto e o problema é que::: o problema é que eu acho que eu não vi muitas aplicações pro que tava naquele texto. Eu tava muito perdido nesse texto (WKC.1, entrevista realizada em 24 de julho de 2013, ênfases nossas).

Em relação aos desafios apresentados acerca do resumo informativo e de suas especificidades, WKC.-1 'infringe' uma das principais particularidades intersubjetivas relativas ao uso social desse gênero: a síntese. o desafio para o acadêmico concretiza-se em diferentes frentes: a função social do gênero, informações relativas à esfera, ao suporte e à datação histórica e à organização espacial desse gênero. Tais dificuldades desencadeiam violações relacionadas à configuração composicional, ou seja, à A produção
textual
na esfera
acadêmica seleção dos procedimentos composicionais para a organização, disposição e acabamento da totalidade discursiva. Em se tratando do conteúdo temático, a orientação do sentido, a finalidade e o objeto do discurso não encontram sustentação nas práticas de letramento do participante a ponto de que os recursos linguístico-textuais-discursivos sejam organizados em favor de um projeto de dizer que se constitua como ato, como participação efetiva por parte do graduando, o que teria implicações em sua apropriação conceitual da discussão materializada no resumo e decorrente da leitura da obra solicitada pela docente.

Emerge, em (2), ainda, uma discussão relativa à dimensão da configuração composicional, à estrutura do texto que compõe e também diferencia um gênero do outro. WKC.-1 questiona-se a respeito dessa diferença e evidencia uma dificuldade discutida por Lillis (2001), Zavala (2010), Lea e Street (1998), e por Ivanic (1998) a respeito do que entendemos como resumo, como resenha, como artigo e da forma como abordamos as relações estabelecidas por meio desses gêneros em se tratando de sua especificidade intersubjetiva. Para Bakhtin (2010 [1952-53]), em cada esfera existem e são empregados gêneros atrelados às condições específicas da esfera e do cronotopo e, mediante tais condições, entram em cena elementos relacionados à temática, ao estilo e à composicionalidade. A questão volta-se, então, para o reconhecimento de uma organização dos dizeres em relação à estrutura, à argumentação, ao posicionamento do sujeito que se enuncia no gênero, à articulação das vozes que se materializam por meio das citações e de seus usos e finalidades, o que requer, nesse contexto, experiências em torno de tais rotinas. 
No que tange aos aspectos relativos aos pressupostos da Linguística Textual, considerando desafios concernentes ao ato de dizer no gênero resumo informativo, importa considerar também a articulação en-

Mary tre os fatores de textualidade e os obstáculos relativos à compreensão Elizabeth das especificidades desses fatores: em relação ao que toca ao conteúdo Cerutti- temático e à informatividade, enfatiza-se uma dificuldade para aborRizzatti dar informação dada e nova, o que é fundamental pensando no resumo; além disso, observa-se uma dificuldade quanto à intencionalidade, soSuziane pesando os fios lançados pelo autor ao seu leitor potencial ou real, bem da Silva como quanto à situacionalidade, já mencionada na relação com a esfera, Mossmann suporte, tempo e espaço.

Prosseguindo a análise, acerca do conteúdo temático, chama-se a atenção para o fato de que os graduandos problematizam a questão dos conhecimentos prévios - conteúdo, composicionalidade e estilo, associados aos fatores de textualidade, relativamente aos conhecimentos de mundo, linguístico e interacionais - no âmbito da unidade temática, o que também parece se estender para a dimensão da configuração composicional, considerando menção à citação e compreensão da legitimação de dizeres. As dificuldades relatadas acerca do ato de dizer na dimensão do conteúdo apontam para uma premência referente ao trabalho com as estratégias implicadas no dizer, considerando compartilhamentos de diferentes perspectivas, os quais enriqueceriam as experiências em torno do que o sujeito tem a dizer a respeito de determinados assuntos. Entende-se que essa é uma questão fundamental no que concerne à autonomia dos sujeitos, sendo imprescindível debater tais questões em se tratando de deslocamentos na constituição subjetiva desses graduandos no que tange à sua participação nos eventos de letramento na esfera acadêmica. A seguir, apresenta-se excerto de artigo produzido por GDL.-1 e de fala dessa participante: 


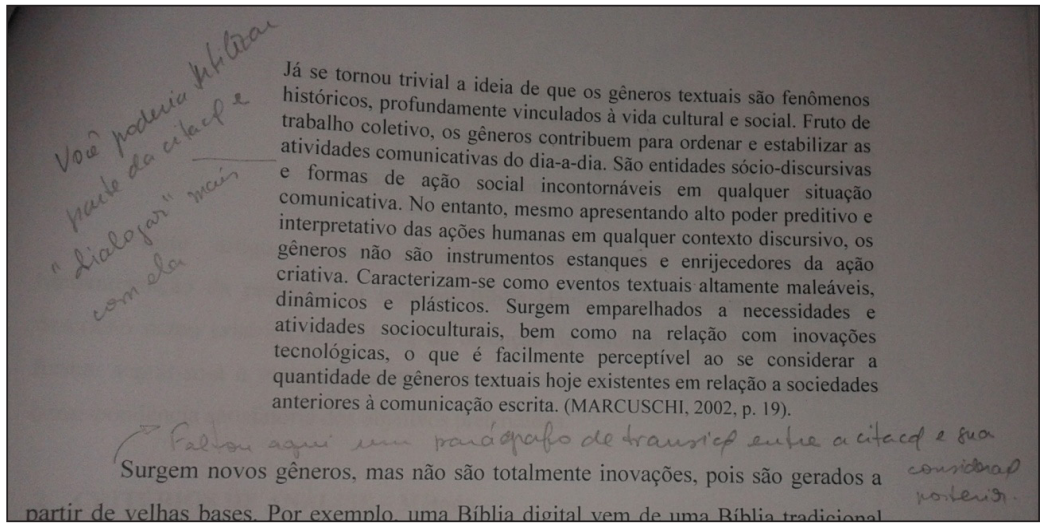

Figura 3 - excerto de artigo produzido por GDL.-1 para a disciplina de Produção Textual Acadêmica. Fonte: Mossmann (2014).

\section{A produção textual na esfera acadêmica}

(3) Então eu olhei aquilo ali e “Ai, como eu vou fazer?" Vou fazer mais ou menos por esse modelo, sem saber realmente como se faz uma citação. Aí, eu percebi que naquele texto tinha detalhamento de certos aspectos, uso de::: citação e aí, eu comecei a usar nos meus textos citações pra dar fundamentação (+) no que eu tava falando. Então, no início foi bem assim, foi uma coisa solta, eu não tinha uma base, tinha só um exemplo a ser seguido (GDL.-1, entrevista realizada em 09 de julho de 2013, ênfases nossas).

Em relação aos dados apresentados acima, considerando os desafios para a produção textual de gêneros na esfera acadêmica, importa observar a complexidade da articulação da voz da acadêmica no processo do discurso reportado, o que se pode relacionar à composicionalidade do gênero, ao conteúdo temático e ao estilo de que se lança mão ao produzir um artigo acadêmico, bem como à intertextualidade, de modo que o foco recai sobre as vozes pertencentes à cadeia discursiva e à urgência de se realizar recortes, costuras, tessituras, paráfrases, utilização de discurso direto e indireto. A dificuldade parece também se configurar de modo mais efetivo em decorrência da artificialidade constitutiva do deslocamento do gênero de seu uso real, para um uso ainda tomado em nível de treinamento. Nesse sentido, partindo das discussões vigotskianas, parece relevante enfatizar o movimento de GDL.-1 convergente com a fase da imitação, sendo um 
momento da aprendizagem, uma baliza para o ato de dizer em condições que exigem um percurso de vivências na esfera em questão que enriqueça o desenvolvimento da graduanda em se tratando de sua

Mary apropriação conceitual e que depende do processo estabelecido e maElizabeth terializado por ela em (3).

Cerutti-

Os desafios do ato de dizer no que se refere à questão do discur-

Rizzatti so reportado implicaria que os sujeitos trouxessem para seus dizeres, assim como fazem na vida nas mais diferentes situações, projetos de Suziane dizer compatíveis com o que se espera na esfera acadêmica, tornandoda Silva -se parte das atividades cotidianas de maneira mais efetiva, dialogando com outras vozes. A participação dos graduandos, nesses termos, parece não contemplar os subentendidos atrelados a esse simpósio, haja vista que os sujeitos precisariam vivenciar especificidades e particularidades relativas aos gêneros do discurso em sua condição real, o que implicaria debruçar-se sobre as leituras requeridas, compreendendo implicações ideológicas ali materializadas, posicionando-se em relação aos dizeres que evocam para o diálogo. Tal atividade envolve compartilhamento de um horizonte espacial, bem como do conhecimento e da compreensão comum de uma determinada situação e ainda de um horizonte de valoração compartilhado na esfera em questão (VOLOSHÍNOV, 2010 [1926]). Essa é apontada como a questão de maior complexidade pelos participantes de pesquisa e todos eles reconhecem a importância de legitimar seus dizeres por meio do discurso de outrem.

A respeito dos recursos linguísticos empreendidos, uma das questões apresentadas como foco de grande aflição por parte dos participantes de pesquisa, apresentam-se os seguintes aspectos concretizados nos feedbacks: problemas de redação, apontamentos referentes a questões gramaticais, questões sintáticas, uso de pontos de interrogação e sinalizações feitas por meio de realces (grifos). Para os graduandos, há uma insegurança que impera diante das solicitações de modificações feitas em relação à dimensão de estratégias linguísticas para as quais eles não apresentam vivências que os auxiliem no reconhecimento dos modos de dizer considerados 'adequados' às especificidades intersubjetivas de cada gênero. A esse respeito, apresenta-se o excerto abaixo e evoca-se a fala de WKC.-1 acerca das dificuldades de se compreender o que é apenas apontado como conhecimento que já devia ter sido apropriado: 
Importante ter em mente a diferença entre gênero textual oral e escrito, pois muito embora os dois estejam relacionados, são muitos os casos em que só podem ser concebidos através de um deles. Como é o caso das notícias da TV, onde elas são geradas em forma escrita, mas são transmitidas por via oral.

Podemos reparar que muitas vezes, em situações orais, os interlocutores discutem sobre o gênero em que vão apresentar, para isso é utilizadê três critérios: meio de comunicação, critérios formais e conteúdo.

Figura 4 - Excerto de resumo informativo de WKC.-1 - disciplina de Produção Textual Acadêmica. Fonte: Mossmann (2014).

\section{A produção \\ textual \\ na esfera \\ acadêmica}

167

Outro aspecto relativo aos desafios do dizer refere-se às normas padrão e ABNT. Os participantes de pesquisa apontam, nesses termos, para dificuldades referentes a saberes normativos que eles deveriam trazer consigo ou que deveriam aprender na disciplina de Produção Textual Acadêmica; no entanto, o foco instrucional e a ausência de experiências e de necessidades em torno das relações estabelecidas por meio dos eventos de letramento acabaram por agir em favor da manutenção das práticas do mistério. Infere-se, assim, que essa dificuldade se configura por conta do não reconhecimento da funcionalidade e da relevância de tais normas para uma participação mais efetiva nos eventos de letramento. Essa questão de apropriar-se ou não dos usos das normas parece periférica, no entanto, é elemento definitivo quando se pensa e se compreende que a participação do sujeito como insider evidencia-se pelo domínio dos diferentes aspectos relativos às demandas acadêmicas.

\section{Considerações finais}

O recorte apresentado neste artigo buscou discutir os desafios atinentes aos usos da escrita materializados em gêneros do discurso da esfera acadêmica, considerando a participação de graduandos do curso de Letras/Por- 
tuguês da Universidade Federal de Santa Catarina, matriculados em $1^{\text {a }}$ fase, na disciplina de Produção Textual. Para tanto, recorreu-se a uma articulação teórica que pudesse dar conta de aprofundar a discussão relativa ao ato

Mary de produzir textos materializados em gêneros do discurso secundários, de Elizabeth modo a problematizar a relevância das ações didático-pedagógicas e das Cerutti- concepções subjacentes aos elementos relativos às teorizações acerca da Rizzatti compreensão de língua, de texto, de gêneros. Importa enfatizar, nesses termos, uma tensão da constituição dos participantes em relação às demandas Suziane acadêmicas para a produção textual, especialmente, quanto às especificida Silva dades intersubjetivas e intrassubjetivas do dizer acadêmico, considerando, Mossmann aspectos interacionais, textuais, linguísticos e normativos.

\section{REFERÊNCIAS}

ANDRÉ, Marli Eliza Dalmazo Afonso de. Estudo de caso em pesquisa e avaliação educacional. 3. ed. Brasília: Liber Livro Editora, 2008.

ANTUNES, Irandé. Lutar com palavras: coesão e coerência. São Paulo: Parábola Editorial, 2005.

BAKHTIN, Mihkail. Filosofia do ato responsável. São Carlos: Pedro e João Editores, 2010 [1920-1924].

Estética da criação verbal. 5. ed. São Paulo: Martins Fontes, 2010 [1952-53].

BARTON, David. Literacy: an introduction to the ecology of written language. 2 ed. UK: Blackwell Publish, 2007 [1994].

BARTON, David and HAMILTON, Mary. Local Literacies: reading and writing in one community. Londres: Routledge, 1998.

CERUTTI-RIZZATTI, Mary Elizabeth; MOSSMANN, Suziane; IRIGOITE, Josa Coelho. Estudos em cultura escrita e escolarização: uma proposição de simpósio entre ideários teóricos de base histórico-cultural na busca de caminhos metodológicos para pesquisas em Linguística Aplicada. Revista Fórum Linguístico. Florianópolis, v. 9. n. 4, 2013. 
CERUTTI-RIZZATTI, Mary Elizabeth; CASSOL DAGA; Aline; CATOIA DIAS, Sabatha. Intersubjetividade e intrassubjetividade no ato de ler: a formação de leitores na Educação Básica. Calidoscópio. v. 12, n. 2, p. 226-238, mai./ago., 2014.

CHAROLLES, Michel. Introdução aos problemas da coerência dos textos. In: GALVES, Charlotte; ORLANDI, Eni P.; OTONI, Paulo (Orgs.). 0 texto: leitura e escrita. 2. ed. Campinas: Pontes, 1997 [1978]. p. 39-90.

CORREIA. Karoliny. 0 ato de dizer na esfera escolar: reverberações do ideário histórico-cultural no ensino da produção textual escrita. (Mestrado em Linguística). Universidade Federal de Santa Catarina, Florianópolis, 2013.

A produção textual na esfera acadêmica

DUARTE, Newton. Individualidade, conhecimento e linguagem na concepção dialética de desenvolvimento em Vigotski. Revista Fórum Linguístico. Florianópolis, v. 13. n. 4, 2016.

HAMILTON, Mary. Expanding the new literacies studies: using photographs to explore literacy as social practice. In: BARTON, David; HAMILTON, Mary; IVANIC, Roz. (Orgs.). Situated Literacies: Reading and Writing in Context. Londres: Routledge, 2000.

HELLER, Agnes. 0 cotidiano e a história. 10. ed. São Paulo: Paz e Terra, 2014 [1970].

IVANIC, Roz. Writing and identity: the discursive construction of identity in academic writing. Amsterdam: John Benjamins, 1998.

$\mathrm{KOCH}$, Ingedore. Desvendando os segredos do texto. São Paulo: Cortez Editora, 2002.

LEA, Mary R.; STREET, Brian V. Student writing in higher education: an academic literacies approach. Studies in Higher Education. V. 23, p. 157, 16p, 1998.

LILLIS, Theresa M. Student Writing: access, regulation, desire. Londres: Routledge, 2001. 
MASON, Jennifer. Qualitative researching. London: SAGE Publications, 1996.

Mary MOSSMANN, Suziane da S. 0 ato de dizer entre Babel e PenteElizabeth costes: um estudo sobre os usos sociais da escrita na esfera Cerutti- acadêmica. Dissertação (Mestrado em Linguística) - Universidade Rizzatti Federal de Santa Catarina, Programa de Pós-graduação em Linguística. Florianópolis, 2014.

Suziane

da Silva PONZIO. Augusto. Procurando uma palavra outra. São Carlos: Mossmann Pedro e João Editores, 2010.

170 STREET, Brian V. Literacy in theory and practice. Cambridge: Cambridge University Press, 1984.

VIGOTSKI. A formação social da mente. São Paulo: Martins Fontes, 2000 [1968].

VOLÓSHINOV, Valentín Nikoláievich. El marxismo y la filosofia del lenguaje. Buenos Aires: Ediciones Godot, 2009.

A construção da enunciação e outros ensaios. São Carlos: Pedro e João Editores, 2013 [1930]).

ZAVALA, Virginia. Quem está dizendo isso? Letramento Acadêmico, identidade e poder na educação. In: VóVIO, Cláudia; SITO, Luanda; DE GRANDE, Paula (Orgs.). Letramentos: rupturas. Deslocamentos e repercussões de pesquisas em linguística aplicada. Campinas: Mercado de Letras, 2010, p. 71-95.

Recebido em 06 de março de 2017.

Aceito em 05 de maio de 2017. 